\title{
IS ONE TIME-SERIES IN THE BUSINESS TENDENCY SURVEY ABLE TO PREDICT ANOTHER ONE? - GRANGER CAUSALITY BETWEEN TIME SERIES
}

\author{
VERONIKA PTÁČKOVÁa,b, ${ }^{\mathrm{a}}$, LUBOMÍR ŠTĚPÁNEK ${ }^{\mathrm{c}}$, VÍT HANZAL ${ }^{\mathrm{c}}$ \\ veronika.ptackova@vse.cz, lubomir.stepanek@vse.cz,xhanv16@vse.cz
}

\footnotetext{
a University of Economics, Prague, Faculty of Informatics and Statistics, Department of Economic Statistics, W. Churchill Sq. 4, Prague, Czech Republic

b Czech Statistical Office, Department of Business Tendency Surveys, Na padesátém 81, Prague, Czech Republic

c University of Economics, Prague, Faculty of Informatics and Statistics, Department of Statistics and Probability, W. Churchill Sq. 4, Prague, Czech Republic
}

\begin{abstract}
A Business Tendency Survey (BTS) is one of popular instruments used for providing rough forecasts of future conditions of the national economy. Economists, journalists and analysts are not the only ones interested in the future development of the economy; ordinary citizens are also attentive to such forecasts. The Czech Statistical Office publishes results of the BTS in two forms: balance, and basic indices, respectively. The paper focuses on the base of basic indices, and investigates why the base is different for different European countries and protracts attention to a related question whether a point estimate such as a base year or long-term average is suitable for the Czech Republic. The aim of the paper is to find the most suitable base for the Czech Republic in terms of getting the tightest match between the obtained and predicted values of economic indicators. Findings from this study should be important for obtaining better predictions and enhancing capabilities of the BTS.
\end{abstract}

\section{Key words}

Business Tendency Survey (BTS), confidence indicator, short-term statistics, base of basic indices

\section{JEL classification}

$\mathrm{C} 10, \mathrm{C} 22$

\section{Introduction}

Business and consumer surveys are realized cross all European countries. A large number of students and research institutions focus on obtaining better indicators of a future economy development. Thanks to the harmonisation, the results are intensively used for short-term analyses and forecasting of economic activity, or they are widely used to assess the current economic developments in Europe. Surveys are necessary for official statistics because countries publish qualitative data earlier than quantitative data from other surveys about key areas of the national economies (European Commission, 2019). On the other hand, there are many disadvantages: data are qualitative, and they have to be transformed somehow before being added to forecasting models. Another problem is the weighting scheme (Emerson and Hendry, 1998) affecting importance of individual inputs going into the analyses.

Authors want to improve the quality of the Business Tendency Survey (BTS). The results of this survey are published in the following two forms: (i) basic indices, and (ii) balance, respectively. The first option basically opens a discussion about the base of the basic indices. According to the European Commission, the base should be a long-term average (LTA), but some European states, especially in Central Europe, do not share the approach adopting the 
common long-term average, but prefer to have own, different base. Upon reviewing the literature, we are going to discuss which base is the most suitable for the Czech Republic.

We divided the paper into three chapters. The first is a literature review about the BTS - its calculation and interpretation. The second chapter describes our analysis we have suggested. The last but not least one presents the most important results of the calculation we have got so far and includes a discussion about the usage of the basic indices.

\section{Literature review}

The BTS is a useful instrument for obtaining appropriate signals on economic developments. The survey gives information about the development of main areas of the enterprise economy for the next few months. In conclusion, we can say that the surveys are the essential data source for countries which are based on market relations (Czech Statistical Office, 2019).

Directorate-General for Economic and Financial Affairs (DG ECFIN) decided to set a starting point of these surveys on 15 November 1961. The first one was about the manufacturing sector in 1962. After that, in 1966, the construction sector and investment plans in the manufacturing sector were added, consumer extended business surveys in 1972 and eventually, retail trade was added in 1984. Finally, the service sector was analysed in 1996 for the first time. The Commission started to analyse the financial sector at the European Union and Euro-area level in 2007 (European Commission, 2019).

It is important to say that the BTS collects qualitative data. The collected qualitative data are very useful in terms of they describe and represent the business companies' opinions though the surveys work with incomplete information and they describe only expectations of the economic environment (Kokocińska and Strzała, 2008). The questionnaires include questions about stocks, a firm's current and future situations, employment or insolvency. The respondents can choose from the following (typically three) options: "improve", "no change", or "deteriorate", respectively. These questionnaires focus on four business areas: industry, construction, trade and selected services, respectively. After that, analysts in the institutions calculate a compose an overall confidence indicator - Economic Sentiment Indicator (ESI) which can be written as a weighted average of seasonally adjusted confidence indicators - i. e. in the industry, in the construction, selected services and the trade, respectively - and a consumer confidence indicator. Similarly, the business confidence indicator is an average of seasonally adjusted confidence indicators in industry, construction, trade and selected services, respectively. The consumer confidence indicator is constructed as an average of four indicators: expected financial situation of consumers, expected total economic situation, expected total unemployment and finally saving scheduled in the next 12 months (Czech Statistical Office, 2019), respectively. It is essential to mention that the indicators are weighted during the calculation of the composite confidence indicator (Economic Sentiment Indicator), see Figure 1. These values are published on a monthly basis.

There are several ways how to publish the final results. The Czech Statistical Office uses basic indices' approach. Nowadays, i. e. in year 2019, the base year of the basic indices' approach is the average of the year 2005. Not only the Czech Statistical Office presents their results based on basic indices. The vast majority of countries follows the European Commission recommendations (see the next paragraph for more information), however there are some states not adopting the recommendations which take a different approach. Table 1 describes the base of basic indices' approach for confidence indicators (CI) in 2019 in selected European countries. 
Figure 1: Weighing system for construction of composite confidence indicator

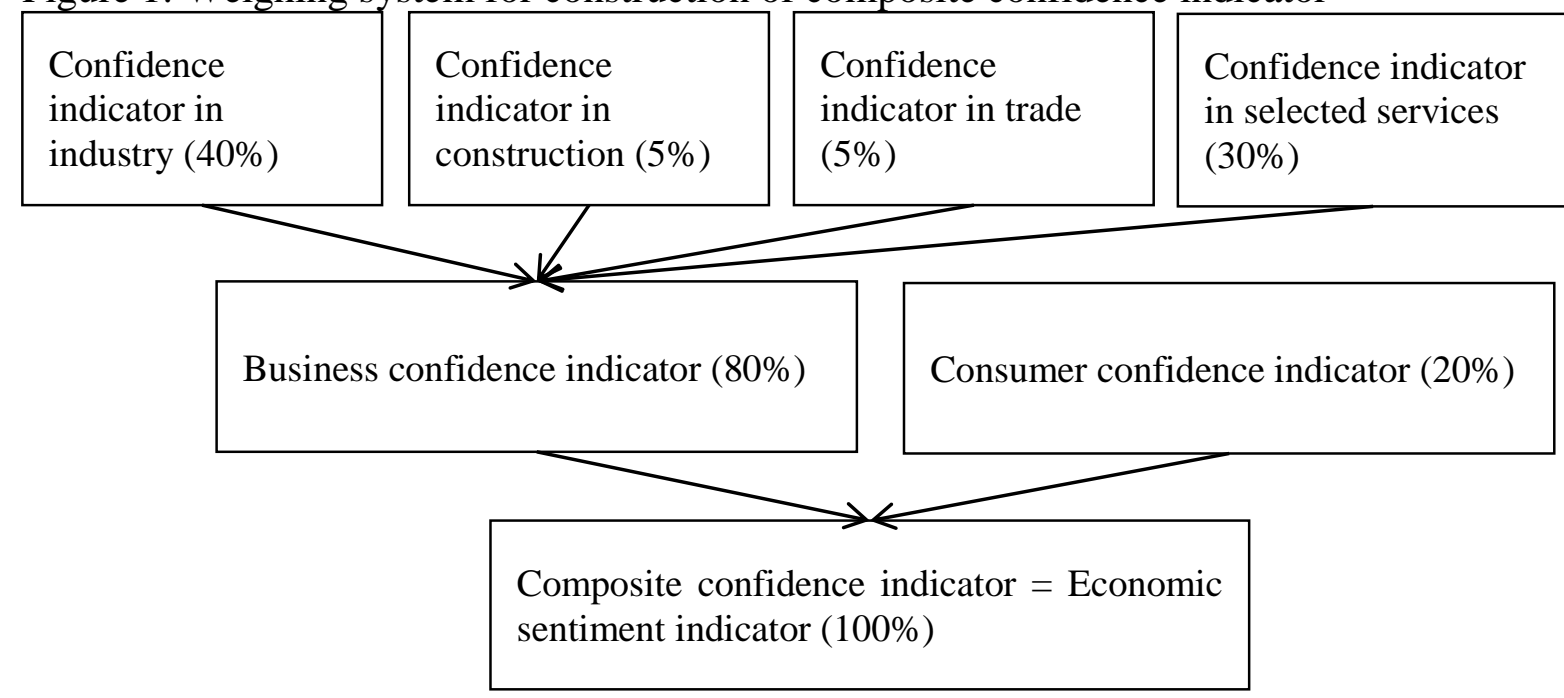

Source: the authors.

Table 1: The base of basic indices for confidence indicators in 2019 across European countries

\begin{tabular}{cc}
\hline Country & Base of basic indices for CI \\
\hline Czech Republic & average of 2005 \\
Germany & average of 2015 \\
Italy & average of 2010 \\
Slovakia & average of 2015 \\
\hline
\end{tabular}

Source: the authors.

Using the basic indices, we can compare results over a period of time. The European Commission recommends the long-term average as a base of basic indices for the confidence indicators. The long-term average currently used by the European Commission is calculated over the period 1990 - 2018. For countries where the European Commission does not have survey data going back until 1990, the period is considered to start at the earliest available data point onwards to 2018. Every January, the European Commission revises the data to include an additional year in the standardisation process (i. e. in January 2020, the European Commission is going to review the European Sentiment Indicator so that it will be based on an average stretching from 1990 to 2019).

The advantage of the basic index is that it shows the development of a raw of numbers over time. In fact, it is not in a real value (euro, tons, etc.), but the index describes the change of the development - in this specific situation, the confidence in the specific area or even whole economy (Eurostat, 2019). Index numbers can guarantee a certain standardised approach to measure any developments of observed values, one of their basic advantages is not only the fact they can express the development through time, but they also can be used for analyses of multiple adjacent periods, which could be better interpreted than balance between two periods only (Das, 2012). Assuming the above calculations, we have to accent a careful and thoroughgoing performing of the constructions and interpretations since that the results can be sensitive to the type of analysed economic units and other market conditions (Fisher and Shell, 1998).

The second form of the results is a balance in sense of a percentage difference between the responses "growth" and "fall". This approach is very popular and easy-to-follow thus we can find these results even more often than basic indices' calculations on the European institution website (European institutions - which publish the results based on the BTS - are listed on the European Commission website). End-users usually prefer the balance because it is easy-tounderstand, more straightforward and easier for interpretation. Positive values of the balance 
could signal an optimistic business climate whereas negative values may imply a pessimistic business climate. The balances are used for the calculation of the confidence indicator mentioned above (as the arithmetic average of the balances - in percentage points - of the specific questions from the questionnaire).

Analysts often discuss what Economic Sentiment Indicator actually describes or predicts. Some of the analysts claim the Economic Sentiment Indicator predicts the gross domestic product (GDP) or gross value added (GVA) and indeed, we can read in some articles the Economic Sentiment Indicator follows in time a similar development as the above mentioned economic indicators. Nowadays, analyst try to find the indicator what ESI (or its specific confidence indicator) has got the strongest association to. Kaufmann and Scheufele (2017) reviewed their work and contradicted their results. They declared the survey does not contain any pieces of information for the GDP growth but the survey is useful for the forecasting the medium-term CPI inflation. According to Biau et al. (2007), services can help with the estimate of the GDP. Cesaroni (2011) contributed with the fact that results arising from the BTS are not influenced only by the GDP but also by the economic cycle as well. Finally, Čižmešija and Orlović (2018) confirmed the relationship between future (changes in consumer confidence indicator) and obtained changes in turnover in the retail trade.

In the introduction, we mentioned that the BTS could help to predict the economic indicators. We considered this fact as a motivation why we focus on the following question: Does a change in the basic indices have an impact on the results? If yes, what base is the best for the Czech Republic in terms of getting the tightest relations between the obtained and predicted values of the indicators?

\section{Methods and results}

\subsection{Development of the indicators in the Czech Republic}

In our analysis, we focused on the Economic Sentiment Indicator (ESI) which was established in order to predict a development of the gross domestic product (GDP) or gross value added (GVA). In the beginning, we should mention that a change in the base year can give a more realistic picture of the level shift in the near future's economy. The basic indices will be calculated in forms:

- average of 2005 ,

- average of 2010 ,

- average of 2015 ,

- long-term average (2003 - 2017).

Many European countries change the base of the basic indices every five years. To the date of this paper publishing, the Czech Republic uses an average of 2005 as the base (but it will be probably changed). The main argument for the base's switch is that Czech authorities would like to have the same base as Germany since that the German economy has the most significant impact on the development of the Czech economy. However, as we have stated before, the European Commission recommends a long-term average. The four approaches of the calculation based on three different bases and one long-term average, respectively, are displayed in Figure 2. Data are available on the Czech Statistical Office website ${ }^{1}$.

Figure 2 has a month of the survey (from January 2003 to December 2018 - quarterly) on the horizontal axis, and the value of the ESI (in percentage) is on the vertical axis. Figure 2 shows that the most optimistic could be the development depicted using the basic index (base in 2010). While the ESI (2015) and ESI (LTA) have similar growth, the ESI (2005) development is the most pessimistic one. Taking account only into the Figure 2, we can agree

\footnotetext{
${ }^{1}$ Available at: https://www.czso.cz/csu/czso/kpr_cr (accessed: 2019-05-13).
} 
with the European Commission that the long-term average - as a middle variant of these four approaches - seems to be the most realistic. Afterwards, we contributed with an analysis which can help us in choosing the best base of indices for the Czech economy. We want to answer the following question: What base (if any) is the most suitable for the prediction of Czech economic development?

Figure 2: Development of monthly ESI basic indices - base in 2005, 2010, 2015 and LTA (in \%)

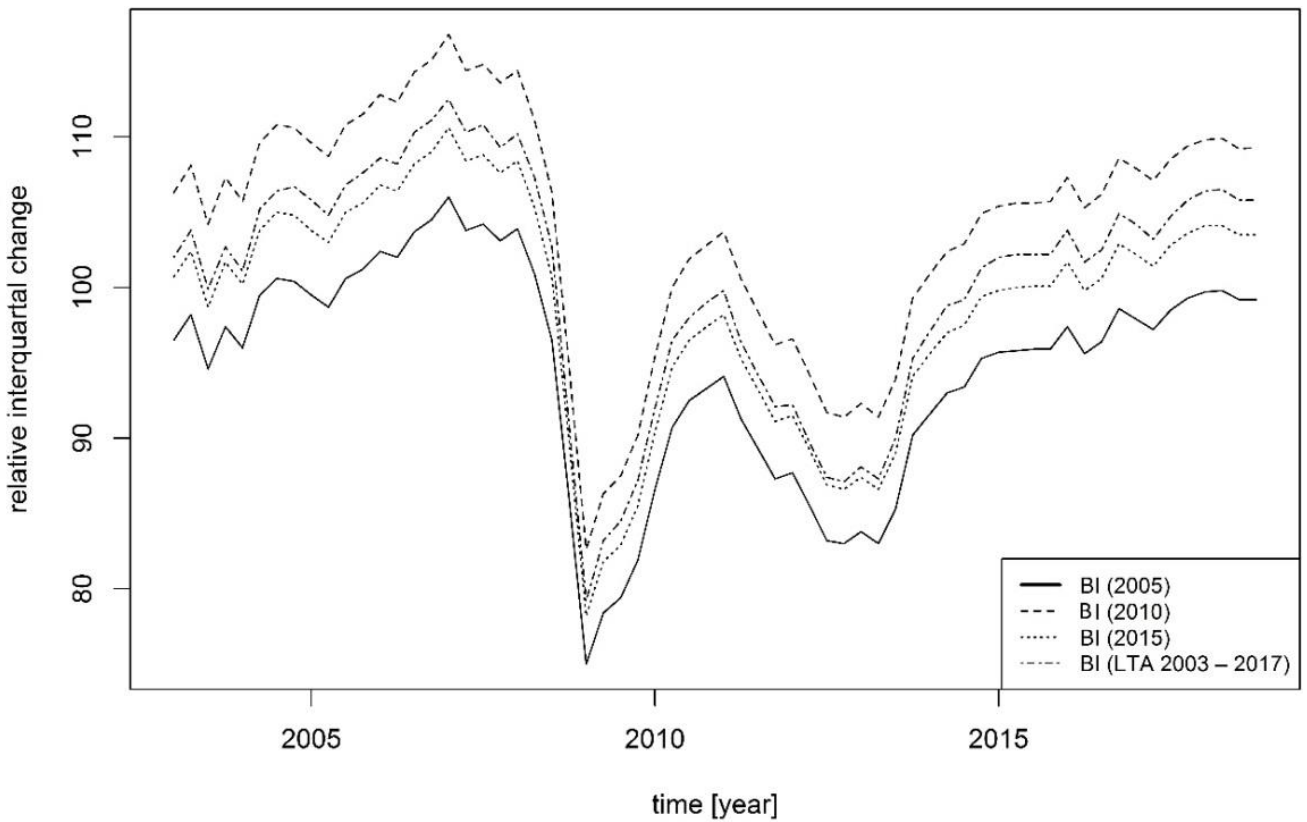

Source: the authors.

\subsection{Motivation and methods}

The aim of the paper is finding the base of the Economic Sentiment Indicator in terms of getting the tightest relations between the obtained and predicted values of the economic indicators. The base considered in the analysis will be selected from the fourth options and, moreover, predictions based on an individual base will be compared to each other. As an a priori assumption which is the following analysis based on, we suppose that Economic Sentiment indicator, used in the analysis, should predict the GDP (GVA) in the next consecutive three months.

\subsubsection{Data}

Data were seasonally adjusted using X-13 Census ARIMA procedure and a linear trend was extracted from the data such that all time-series were de-trended by doing the decomposition (we got data devoid of a trend after this step). Both deseasoning and detrending are approaches for stationarization of economic time-series. To be more specific, we estimated the trend and after that we calculated deviations from the trend by subtraction of the trend from the original raw time-series. This method is used within real variables such as real GDP, real wages or real money balances (Hloušek, 2019).

Then, we tested the stationarity of all the time-series - in other words, we checked whether the time-series are stochastic stable through the time. In order to address this, we used the augmented Dickey-Fuller test, which is one of the most popular test for unit root testing. The mentioned test is based on the model of the first-order autoregressive process AR(1) (Box and Jenkins, 1970) 


$$
y_{t}=\varphi_{1} y_{t-1}+\varepsilon_{t}, \quad t=1, \ldots, T
$$

where $y_{t}$ and $y_{t-1}$ are two consecutive observations of the time-series in times $t$ and $t-1$, respectively, $\varphi_{1}$ is the autoregression parameter, $\varepsilon_{t}$ is the non-systematic component of the model with the white-noise process characteristics. The null hypothesis is $H_{0}: \varphi_{1}=1$, which would mean that the modelled process contains a unit root, each two consecutive time observations are fully autocorrelated (their coefficient of autocorrelation is equal to unit root, $i$. e. $\left.\varphi_{1}=1\right)$ and therefore the time-series is non-stationary. In case we find that the time-series is non-stationary, we would transform the time series to avoid this phenomena using for example logarithm, other functions or by applying differentiation on the time-series.

\subsubsection{Granger causality}

Granger causality test is a statistical tool to determine if a time series is appropriate for predicting another time series. Mainly, we want to know if a change of one variable has an impact on an appropriate change of the other variable. General definition of the Granger causality is as follows: if the variable $X$ is causal for the variable $Y$ in Granger way, then the variable $Y$ can be predicted more accurately using the information from the variable $X$.

We used a restricted regression model which says that variable $Y$ can be described itself using its own lagged ("past") values (equation 2)

$$
Y_{t}=\alpha_{0}+\sum_{i=1}^{m} \alpha_{i} Y_{t-1}+\mu_{t}
$$

where $Y_{t}$ and $Y_{t-1}$ are two consecutive observations of the time-series in times $t$ and $t-1$, respectively, $\alpha_{0}$ and $\alpha_{i}$ are coefficients of toughness of the dependency between $Y_{t}$ and $Y_{t-1}$ and finally $\mu_{t}$ is a non-systematic (white-noise) component of the model.

The second equation is extended by lagged ("past") values of the variable $X$ considered as an explanatory variable. Equation 3 describes unrestricted regression model

$$
Y_{t}=\alpha_{0}+\sum_{i=1}^{m} \alpha_{i} Y_{t-1}+\sum_{j=1}^{m} \beta_{j} X_{t-j}+\mu_{t}
$$

where $X_{t}$ and $Y_{t}$ are values of the time series $X$ and $Y$ in a time $t$, the $\alpha_{0}$ is a linear constant (needed to be estimated), $\mu_{t}$ is the white noise sequence, $\alpha_{i}$ and $\beta_{j}$ are coefficients determining toughness of the dependency between lagged and present values of the time series and $m$ is the number of lagged terms (Wang, 2019). The null hypothesis of the test says that the variable $X$ does not affect the variable $Y$ in Granger way (no lagged values of $X$ are statistically significantly feasible for the regression model).

\subsection{Results - choosing the base of the ESI in the Czech Republic}

Analysis is focused on data from January 2003 until December 2018 for all sectors (industry, construction, trade and selected services, respectively) and consumers in the Czech Republic. All the computations we performed using $\mathrm{R}$ language and environment for statistical computing and graphics (R Core Team, 2014).

We decided to analyse independently the both economic indicators - GDP and GVA because, as stated in the background section, there is no unambiguous opinion what the BTSs should predict, if either the GDP, or the GVA, or both of them, if any. Therefore, in order to avoid an incorrect omitting of one of the indicators, we expanded our analysis to cover both of the economic indicators (GVA, GDP) supposing they are independent. For example, when we want to analyse and predict the confidence indicator in each area, we would focus on the gross 
added value. Following this way, the gross added value for the whole economy is more useful. Of course, the GDP is even more common and more often published indicator and easier-tofollow for end-users interested in the field. It means that we tested Granger causality between the GDP (or GVA) and the ESI basic indices (with base equal to 2005, 2010, 2015, respectively, and LTA) considering the both variable as time-series. The data we used for purposes of the analysis came from the Czech Statistical Office and Eurostat website. Unfortunately, the GDP and GVA data are based on quarterly basis. It was a reason why we had to calculate quarterlybased basic indices of the Economic Sentiment Indicator as an average of three basic indices (which are based on monthly basis though) of the ESI. We mention here again that the Business Tendency Survey has been defined and established to predict the near future economy (the next consecutive three months). We are going to take into account the shift between predictions and observations and therefore we will find the relationship between value of the Business Tendency Survey in time $t$ and value of the economic indicator in time $t+1$.

In the beginning data were seasonally adjusted and detrended as described above because of their obvious non-stationarity, which was checked using augmented Dickey-Fuller test for the first run. After that, we tested the stationarity of the resulting time-series using augmented Dickey-Fuller test and obtaining the result the time-series are stationary. Claiming this, we can without any limitations apply Granger causality test in order to find an answer to our scientific questions stated above in this paper.

Performed Granger causality test proved that we should take into consideration the basic indices' approach rather than long-term average. It is harder to say which one (base 2005, 2010, or 2015, respectively), because returned $p$-values and $F$-statistics are very similar and the tiny differences are only due to the deseasoning and detrending as indicating the repetition of the analysis using non-adjusted (in terms of a trend or seasonality) data resulting in exactly the same $F$-statistics and $p$-values for all basic indices. However, we got the best results, i. e. the largest value of F-statistic and the lowest value of p-value, for the base equal to 2010, and - in comparison - for the same year we got the worst results (with the weakest predictive power in Granger way) when considering LTA based approach for the indicators' calculations. The logic behind the almost-same F-statistics and $p$-value for all three different bases could be in manner of Granger test - an amount of information in BTS's time series is in practise the same regardless the fact what the base year in fact is. Long-term average $(2003-2017)$ shew a bit worse outcome (see Table 2) in sense of the prediction of near future of economy. In our opinion, LTA has worse results because of the significant break-in peaks in the considered time range. Saying that, peaks in the business cycle (especially in the development of the GDP or GVA) are the most important when one tries to interpret significant impacts on near economic future. To conclude that, we should calculate the development of the GDP and GVA rather with the basic indices - ESI (2005), ESI (2010) or ESI (2015) in the Czech Republic (the base year itself is not so important as was shown above).

Table 2: Granger causality tests

\begin{tabular}{lcccc}
\hline & \multicolumn{2}{c}{ ESI_BI $(2005,2010,2015)$} & \multicolumn{2}{c}{ LTA $(2003-2017)$} \\
\hline & P-value & F-test & P-value & F-test \\
GDP (BI = 2005) & 0.3182 & 1.0136 & 0.3503 & 0.8864 \\
GDP (BI = 2010) & 0.2713 & 1.2332 & 0.3018 & 1.0850 \\
GVA (BI = 2005) & 0.3264 & 0.9795 & 0.3586 & 0.8561 \\
GVA (BI = 2010) & 0.3572 & 0.8610 & 0.3913 & 0.7458 \\
\hline
\end{tabular}

Source: the authors.

Our results are confirmed in Figure 3 - 4. Figure 3 describes the development of the GDP $(B I=2005)$ and the four ESI's such that base is the average of 2005, the average of 2010, the average of 2015 and the long-term average, respectively. All time-series are not seasonally 
adjusted in the figure (in opposite to this, the results are calculated on the seasonally adjusted and detrended values in Table 2).

Figure 3: Development of GDP $(\mathrm{BI}=2005)$ and ESI basic indices - base in years of 2005, 2010, 2015, respectively, and LTA (in \%)

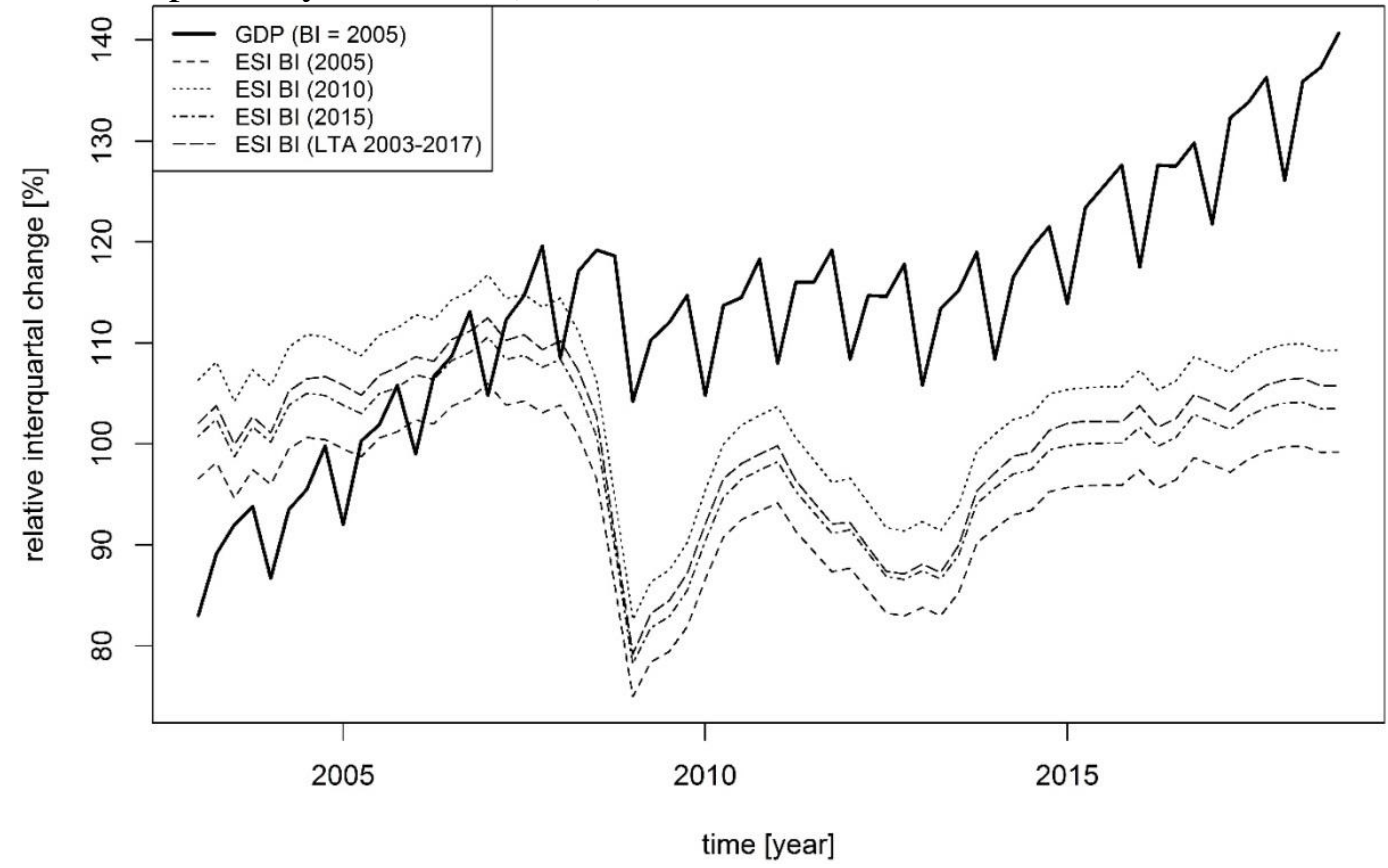

Source: the authors.

Figure 4 describes the development of the GDP $(B I=2010)$ and the four ESI's such that base is the average of 2005, the average of 2010, the average of 2015 and long-term average, respectively.

Figure 4 Development of GDP $(B I=2010)$ and ESI basic indices - base in years of 2005, 2010, 2015, respectively, and LTA (in \%)

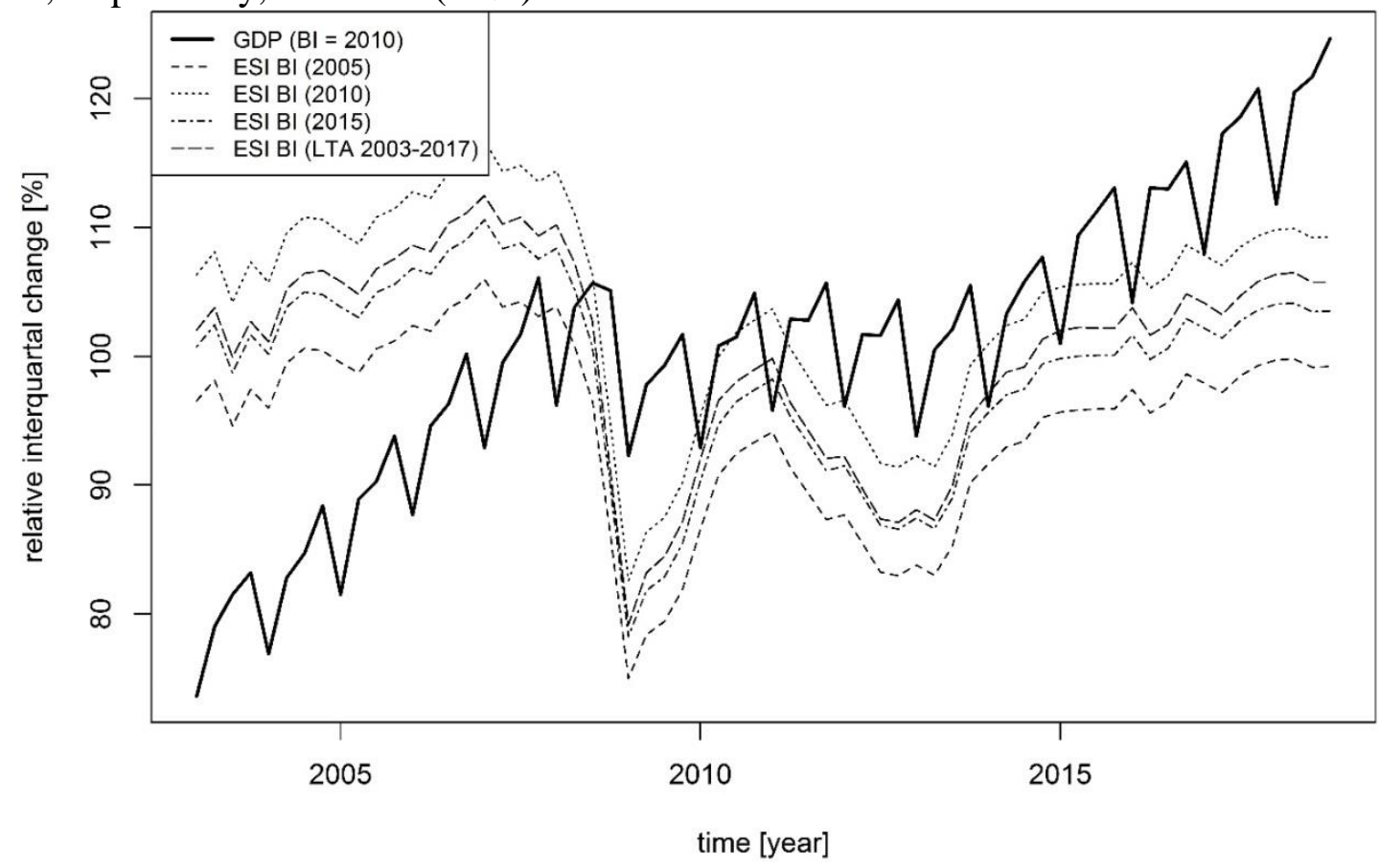

Source: the authors. 
In Figures 3 and 4 we cannot see significant differences between the variables, which is mainly due to the fact that the plotted time-series are neither seasonally adjusted nor detrended, therefore, in order to make a choice for the best fitting base, we have to rely on the results of the Granger causality test which help us with such a choice and which is based on data considering both deseasoning and detrending. It is important that the results of the Business Tendency Survey confirmed the real development of the gross domestic product, especially gross value added.

\section{Conclusion}

As we said before, the Business Tendency Survey is a crucial instrument for the prediction of the Czech economy. The results we have conducted confirmed N. G. Das (2012) claiming that the basic indices are significant and useful for future research and discussion regarding the significance, benefits of the mentioned survey and predictions based on it.

Many authors discuss which economic indicators are in fact predicted by Business Tendency Survey. We focused both on GDP and GVA - both of them are basic indices. Using Granger causality tests, we confirmed that the Business Tendency Survey has better results with the analysed economic indicators (in terms of getting the tightest relations between the obtained and predicted values of the economic indicators) and we should calculate with the basic indices within the base given as an average of 2005, 2010 or 2015 years, respectively, rather than with the long-time average. The long-term average (which is recommended by the European Commission) has shown a bit worse results for the used data, which came from the Czech Republic economy environment.

For the next research, we could extend our analysis in the following way; firstly, we can analyse whether the accurate confidence indicator (in the industry, selected services, construction and trade, respectively) does demonstrate better prediction ability for the gross value added in the selected areas of the interest, or does not. Once we could approve that the mentioned confidence indicators are able to help us with the predictions, we can also address another issue coming together within the results of the BTS - for example weighting system used for construction of the composite confidence indicators.

\section{Acknowledgements}

This paper was supported by the University of Economics in Prague under the grant scheme IGA No. F4/14/2018 "Business tendency survey in the Czech Republic and possibilities of increasing its predictive ability" as well as by the long-term research scheme of the Faculty of Informatics and Statistics at the University of Economics in Prague.

\section{References}

[1] Biau, G. et al. 2008. Nonparametric forecasting of the manufacturing output growth with firm-level survey data. In Journal of Business Cycle Measurement and Analysis, 2007, vol. 3, pp. 317-331.

[2] Box, G. E., Jenkins, G. E. 1970. Time series analysis: Forecasting and control. San Francisco : Holden Day, 1970.

[3] Cesaroni, T. 2011. The cyclical behavior of the Italian business survey data. In Empirical Economics, 2011, vol. 41, iss. 3, pp. 747-768.

[4] Czech Statistical Office 2019. Business cycle surveys - methodology. [cit. 04-02-2019] https://www.czso.cz/csu/czso/business_cycle_surveys.

[5] Čižmešija, M., Orlović, Z. 2018. Consumer confidence indicator as a leading indicator of changes in retail trade turnover. In Ekonomski pregled, 2018, vol. 69, iss. 1, pp. 3-19. 
[6] Das, N. G. 2012. Statistical methods (combined edition, Volumes I \& II). New Delhi : McGraw-Hill, 2012. ISBN 9780070083271.

[7] Emerson, R. A., Hendry D. F. 1998. An evaluation of forecasting using leading indicators, In Journal of Forecasting, 1998, vol. 15, iss. 4, pp. 271-291.

[8] European Commission 2019. The joint harmonised EU programme of business and consumer surveys. User guide. [cit. 2019-02-04] https://ec.europa.eu/info/sites/info/files/ bcs_user_guide_en_0.pdf.

[9] Eurostat 2019. Beginners: Statistical concept - index and base year [cit. 2019-03-18] https://ec.europa.eu/eurostat/statistics-explained/index.php? title=Beginners:Statistical_co ncept_-_Index_and_base_year.

[10]Fisher, F. M., Shell, K. 1998. Economic analysis of production price indexes. Cambridge: Cambridge University Press, 1998. ISBN 0-521-55416-0.

[11]Hloušek, M. 2019. Stationarity. [cit. 2019-05-30] http://www3.econ.muni.cz/ hlousek/ teaching/stationarity.pdf.

[12]Kaufmann, D., Scheufele, R. 2017. Business tendency surveys and macroeconomic fluctuations. In International Journal of Forecasting, 2017, vol. 33, iss. 4, pp. 878-893.

[13]Kokocińska, M., Strzała, K. 2008. Using business tendency surveys for short-term forecasting of macro-categories. An econometric approach. In Prace i Materiały Instytutu Rozwoju Gospodarczego SGH, 2008, vol. 79, pp.7-22.

[14]R Core Team 2014. R: A language and environment for statistical computing. Vienna : R Foundation for Statistical Computing, 2014, http://www.R-project.org/.

[15] Wang, X. 2019. A Granger causality test of the causal relationship between the number of editorial board members and the scientific output of universities in the field of chemistry. In Current Science, 2019, vol. 116, iss. 1, pp. 35-39. 